Harold A. McAlister and William I. Harkopf (eds.)

\title{
Speckle Observations of Triple Stars
}

\author{
SYUZO ISOBE \\ National Astronomical Observatory, Mitaka - shi, Tokyo 181, Japan \\ NAOSHI BABA \\ Faculty of Engineering, Hokkaido University, Sapporo, Hokkaido, Japan
}

\section{OBSERVATIONS}

Our speckle observations were started in 1987 using a 212-cm telescope at San Pedro Martir Observatory in Mexico. A D-IMOSS camera was used until 1990 and an I-CCD camera was introduced in 1991. The old camera has only $0^{\prime \prime}: 20$ angular resolution because of an aging effect in its intensifier, while the new camera has 0.06 angular resolution, which is nearly equal to the diffraction limit of the telescope. 128 visual binary stars and 755 spectroscopic binary stars have been observed. The numbers of stars and observations each year are shown in Table 1 and all the observed data are given in a series of papers by Isobe $e t$ al. (1990a, 1990b, 1992a) and Miura et al. (1992).

TABLE 1. Numbers of observations, stars, and detections in each year.

\begin{tabular}{|lccccc|}
\hline & $\begin{array}{c}1987 \\
\text { June }\end{array}$ & $\begin{array}{c}1988 \\
\text { October }\end{array}$ & $\begin{array}{c}1989 \\
\text { May }\end{array}$ & $\begin{array}{c}1990 \\
\text { August }\end{array}$ & $\begin{array}{c}1991 \\
\text { July }\end{array}$ \\
\hline Visual binaries & & & & & \\
observations & 25 & 66 & 9 & 39 & 30 \\
stars & 15 & 54 & 7 & 30 & 22 \\
$\quad$ detections & 12 & 35 & 5 & 11 & 19 \\
$\begin{array}{l}\text { Spectroscopic binaries } \\
\text { observations }\end{array}$ & 67 & 55 & 156 & 275 & 245 \\
stars & 57 & 47 & 119 & 272 & 160 \\
detections & 15 & 6 & 12 & 2 & 13 \\
\hline
\end{tabular}

We have reported our detections of triple star systems from the data obtained in 1987 and 1988 (Isobe et al. 1992b, Isobe 1992). In two years, 104 spectroscopic binary stars were observed. 21 out of these 104 stars showed clear fringe structures and should also be called visual binary stars detected by the speckle technique. 13 stars out of these 21 have observed parallax values, yielding estimated linear separations from 4 to $40 \mathrm{AU}$ (astronomical unit). Since these stars are also spectroscopic binary stars, $a \sin i$ (a: semimajor axis, i: orbital inclination) values of the stars are obtained and are in the range 0.01 to 1 AU. This result suggests that these are triple stars with a typical configuration; that is, a star is orbiting at a distance of about $10 \mathrm{AU}$ from the central binary pair with a linear separaton of $0.01 \mathrm{AU}$.

21 out of 57 spectroscopic binary stars observed in 1987 are catalogued as visual binary stars with known parallax (Hirshfeld \& Sinnott 1985). The numbers of stars in each range of logarithmic distance are plotted in Figure 1. 


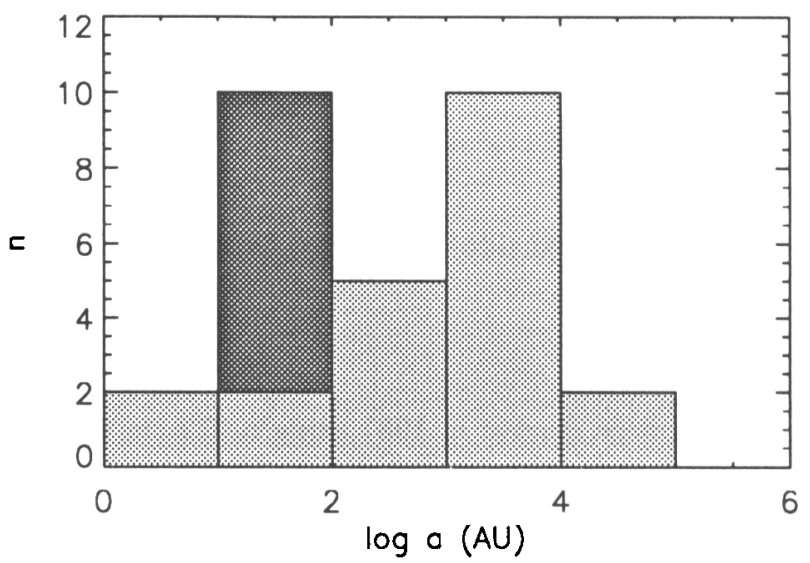

FIGURE 1. Number of visual binary stars with known parallax values observed in 1987 at each logarithmic distance range. Darker hatched areas are numbers of newly detected speckle binary stars.

One can easily see that the peak in the distribution is shifted to large $\log a$ value (from 3 to 4 ). This result is consistent with other statistical studies (for example, Heintz 1978) which claim that the third star of each triple system was captured after star formation in a star cluster. If we add the stars detected by our speckle observations, we have another peak in the distribution. It is very difficult to explain this kind of triple star with short separation (about $10 \mathrm{AU}$ ) by that capture mechanism. We can reasonably conclude that the third stars of our triple star systems with small separation (about $10 \mathrm{AU}$ ) were formed during the same formation period as the close binaries.

Table 2 gives new results obtained from the observations in 1991. 13 stars out of 160 observed spectroscopic binary stars show clear fringe structures with angular separations from 0 ".06 to $1^{\prime \prime} .13$. Unfortunately, only 5 stars have reasonably accurate parallax values, which give linear separations of binary stars detected by speckle technique. It is reasonable to say that the other 8 stars have parallax values smaller than those for the 5 stars; their linear separations are then of the same order or larger than those for the 5 stars. $a \sin i$ values were obtained from spectroscopic observations for all of the 13 stars except HD 196524. Adding these 12 triple star systems from our observations in 1991 gives in total about 40 triple star systems.

Considering our observational limit of angular separation and the small angular separations of our type of triple star systems due to their large distances from the sun, we can conclude that a large fraction of spectroscopic binary stars are in triple systems (or multi-star systems).

Most theoretical calculations (for example, Shu et al. 1987) presently available for star formation processes claim formation of protostellar cores or disks of order several hundred $\mathrm{AU}$, whereas our result claims that a large fraction of triple star systems are formed in a range smaller than several ten AU. 
TABLE 2. A list of objects detected by our speckle observations and some other data for these objects.

\begin{tabular}{|c|c|c|c|c|c|c|c|}
\hline $\begin{array}{c}\text { HD } \\
\text { Number }\end{array}$ & $\begin{array}{c}\text { Spectral } \\
\text { Type }\end{array}$ & Mag. & $\begin{array}{l}\text { Sep. } \\
\left({ }^{\prime \prime}\right)\end{array}$ & $\begin{array}{l}\text { Position } \\
\text { angle }\left({ }^{\circ}\right)\end{array}$ & $\begin{array}{l}\text { Sep. } \\
\text { (AU) }\end{array}$ & $a \sin i$ & $\begin{array}{l}\text { Parallax } \\
\left({ }^{\prime \prime}\right)\end{array}$ \\
\hline $144208 / 9$ & $\mathrm{dF9} / \mathrm{AO}$ & 5.8 & 0.14 & 79 & - & 0.19 & - \\
\hline 145502 & B2IV-V & 4.01 & 1.13 & 0 & 56.3 & 0.014 & 0.020 \\
\hline 145849 & K3III & 5.5 & 0.15 & 86 & - & 1.52 & - \\
\hline 148367 & Am & 4.64 & 0.42 & 45 & 19.1 & 0.087 & 0.020 \\
\hline 162724 & B9V & 5.96 & 0.18 & 97 & - & 0.038 & - \\
\hline 178125 & B7V & 5.10 & 0.31 & 124 & 20.6 & 0.003 & 0.015 \\
\hline 185936 & B5V & 5.95 & 0.20 & 131 & - & 0.011 & 一 \\
\hline 187949 & A2V & 6.47 & 0.24 & 174 & 一 & 0.011 & - \\
\hline 196524 & F5IV & 3.62 & 0.25 & 24 & 9.6 & 5.9 & 0.026 \\
\hline 198743 & Am & 4.72 & 0.06 & 133 & 16.6 & 0.85 & 0.012 \\
\hline 206644 & AOV & 5.74 & 0.19 & 174 & - & 0.017 & -0.002 \\
\hline 207330 & B3III & 4.24 & 0.11 & 113 & - & 0.048 & -0.005 \\
\hline 209791 & Am & 4.29 & 0.07 & 107 & 一 & 1.31 & - \\
\hline
\end{tabular}

Although the number of triple star systems obtained by our speckle observations is not large, our results will give some constraint to the presently developed star formation theory.

\section{REFERENCES}

Heints, W.D. 1978, in Double Stars (Dordrecht, D. Reidel), p. 16

Hirshfeld, A. \& Sinnott, R.W. 1985, in Sky Catalogue 2000.0, (Cambridge, Cambridge University Press), vol. 2

Isobe, S. 1992, Australian J. Astron., Conference Series, in press

Isobe, S., Baba, N., Miura, N., \& Ohtsubo, J. 1992b, ASP Conf. Series, in press

Isobe, S., Norimoto, Y., Noguchi, M., Ohtsubo, J., Baba, N., Miura, N., Yanaka, H., \& Tanaka, T. 1990a, Pub. Nat. Astron. Obs. Japan, 1, 217

Isobe, S., Norimoto, Y., Noguchi, M., Ohtsubo, J., Baba, N., Miura, N., Yanaka, H., \& Tanaka, T. 1990b. Pub. Nat. Astron. Obs. Japan, 1, 318

Isobe, S., Noguchi, M., Ohtsubo, J., Baba, N., Miura, N., Tanaka, T., \& Ni-ino, M. 1992a, Pub. Nat. Astron. Obs. Japan, 2, 459

Miura, N., Baba, N., Isobe, S., Ohtsubo, J., \& Ni-ino, M. 1992, Pub. Nat. Astron. Obs. Japan, in press

Shu, F. H., Adams, F.C., and Lizano, S. 1987, ARA\&A, 25, 23 